\title{
Training understanding of reversible sentences: A study comparing language-impaired children with age-matched and grammar-matched controls
}

Introduction: Many children with specific language impairment (SLI) have problems with language comprehension, and little is known about how to remediate these. We focused here on errors in interpreting sentences such as "the ball is above the cup", where the spatial configuration depends on word order. We asked whether comprehension of such short reversible sentences could be improved by computerized training, and whether learning by children with SLI resembled that of younger, typically-developing children. Methods: We trained 28 children with SLI aged 6-11 years, 28 typically-developing children aged from 4 to 7 years who were matched to the SLI group for raw scores on a test of receptive grammar, and 20 typically-developing children who were matched to the SLI group on chronological age. A further 20 children with SLI were given pre- and post-test assessments, but did not undergo training. Those in the trained groups were given training on four days using a computer game adopting an errorless learning procedure, during which they had to select pictures to correspond to spoken sentences such as "the cup is above the drum" or "the bird is below the hat". Half the trained children heard sentences using above/below and the other half heard sentences using before/after (with a spatial interpretation). A total of 96 sentences was presented over four sessions. Half the sentences were unique, whereas the remainder consisted of 12 repetitions of each of four sentences that became increasingly familiar as training proceeded. Results: Age-matched control children performed near ceiling ( $>=90 \%$ correct) in the first session and were excluded from the analysis. Around half the trained SLI children also performed this well. Training effects were examined in $15 \mathrm{SLI}$ and 16 grammar-matched children who scored less than $90 \%$ correct on the initial training session. Overall, children's scores improved with training. Memory span was a significant predictor of improvement, even after taking 
into account performance on training session 1. Unlike the grammar-matched controls, children with SLI showed greater accuracy with repeated sentences compared with unique sentences. Training did not improve children's performance on a standardized test of receptive grammar. Discussion: Overall, these results indicate that a subset of children with SLI perform well below ceiling even on reversible sentences with three key words and simple syntactic structure. For these children, weak verbal short-term memory appears to impair comprehension of spoken sentences. In contrast to the general finding that rulelearning benefits from variable input, these children seem to do best if given repeated exposure to the same nouns used with a given sentence frame. Generalisation to other sentences using the same syntactic frame may be more effective if preceded by such item-specific learning. 
2 Training understanding of reversible sentences: A study comparing languageimpaired children with age-matched and grammar-matched controls

$6 \quad{ }^{1}$ Current address: Graduate Institute of Audiology and Speech Therapy, National

7 Kaohsiung Normal University, Taiwan.

$8{ }^{2}$ Corresponding author: Department of Experimental Psychology, University of 9 Oxford, OX1 3UD, UK. 10 


\section{PeerJ Reviewing Manuscript}

11

Abstract

12 Introduction: Many children with specific language impairment (SLI) have problems

13 with language comprehension, and little is known about how to remediate these. We

14 focused here on errors in interpreting sentences such as "the ball is above the cup",

15 where the spatial configuration depends on word order. We asked whether

16 comprehension of such short reversible sentences could be improved by

17 computerized training, and whether learning by children with SLI resembled that of

18 younger, typically-developing children.

19 Methods: We trained 28 children with SLI aged 6-11 years, 28 typically-developing

20 children aged from 4 to 7 years who were matched to the SLI group for raw scores

21 on a test of receptive grammar, and 20 typically-developing children who were

22 matched to the SLI group on chronological age. A further 20 children with SLI were

23 given pre- and post-test assessments, but did not undergo training. Those in the

24 trained groups were given training on four days using a computer game adopting an

25 errorless learning procedure, during which they had to select pictures to correspond

26 to spoken sentences such as "the cup is above the drum" or "the bird is below the

27 hat". Half the trained children heard sentences using above/below and the other half

28 heard sentences using before/after (with a spatial interpretation). A total of 96

29 sentences was presented over four sessions. Half the sentences were unique,

30 whereas the remainder consisted of 12 repetitions of each of four sentences that

31 became increasingly familiar as training proceeded.

32 Results: Age-matched control children performed near ceiling ( $>=90 \%$ correct) in

33 the first session and were excluded from the analysis. Around half the trained SLI

34 children also performed this well. Training effects were examined in $15 \mathrm{SLI}$ and 16

35 grammar-matched children who scored less than $90 \%$ correct on the initial training

36 session. Overall, children's scores improved with training. Memory span was a 
37 significant predictor of improvement, even after taking into account performance on

38 training session 1. Unlike the grammar-matched controls, children with SLI showed

39 greater accuracy with repeated sentences compared with unique sentences. Training

40 did not improve children's performance on a standardized test of receptive

41 grammar.

42 Discussion: Overall, these results indicate that a subset of children with SLI perform

43 well below ceiling even on reversible sentences with three key words and simple

44 syntactic structure. For these children, weak verbal short-term memory appears to

45 impair comprehension of spoken sentences. In contrast to the general finding that

46 rule-learning benefits from variable input, these children seem to do best if given

47 repeated exposure to the same nouns used with a given sentence frame.

48 Generalisation to other sentences using the same syntactic frame may be more 49 effective if preceded by such item-specific learning. 


\section{PeerJ Reviewing Manuscript}

50 Introduction

51 For children with specific language impairment (SLI), comprehension of reversible

52 sentences is often a source of particular difficulty (Bishop, 1979; Van der Lely and

53 Dewart, 1986), but the reasons for this are not fully understood. Theoretical

54 accounts range from those that attribute comprehension impairment to auditory-

55 perceptual problems, to those postulating more specific difficulties in mastering

56 syntactic rules, or in carrying out complex syntactic computations (Bishop, 1997).

57 Most research investigating this phenomenon has focussed on reversible active and

58 passive constructions, testing children's ability to comprehend sentences such as

59 "the boy chases the dog", "the dog chases the boy" or "the dog is chased by the

60 boy". Young children may make errors when asked to act out such sentences

61 because they adopt simple strategies such as "pick up the first-named object and do

62 something with it" - a strategy that is usually effective for active sentences but not

63 for passive ones (Van der Lely and Dewart, 1986). As children grow older, errors are

64 more sporadic and less easy to explain in terms of a strategic account. For instance,

65 Bishop (1982) used a multiple choice test, where the correct picture had to be

66 selected from an array that included foils depicting the reversed agent-patient

67 relationship. Although some children systematically misinterpreted all passives,

68 these were unusual cases with severe comprehension problems associated with

69 acquired epileptic aphasia. Other children with more typical language impairment

70 performed below age-level, but their errors were less systematic.

71 Poor comprehension of grammatically complex sentences has been recognised as a

72 problem for many language-impaired children and a handful of experimental

73 interventions have been developed to address these (Ebbels, 2007; Ebbels and Van

74 der Lely, 2001; Ebbels et al., 2014; Levy and Friedmann, 2009; Riches, 2013). To

75 help children overcome comprehension problems, we need to understand the 
76 reasons for their difficulties with these types of construction. One possibility is that

77 perceptual difficulties are implicated. For the child who has difficulty perceiving

78 brief, non-salient morphemes, "the boy is chasing the dog" may be hard to

79 distinguish from "the boy is chased by the dog", leading to poor performance on a

80 multiple-choice comprehension task. A second possibility is that perception is

81 adequate but the complex syntax of active and passive sentences is the stumbling

82 block. Various theories of SLI have proposed difficulties either with specific areas of

83 syntax (Rice et al., 1995), or more generally with the complex computations that

84 are involved in establishing grammatical relationships between different sentence

85 components (Van der Lely, 1996; Van der Lely, 2005). Such accounts cannot explain,

86 though, why children should have difficulty with even simple reversible

87 constructions, namely those using a spatial preposition, such as "the comb is above 88 the flower".

89 Like other open-class words, spatial prepositions are very common in the language.

90 In a rank-ordered list of words in the British National Corpus, the prepositions

91 "before", "after", "above" and "below" occur at ranks 185, 111, 786 and 1656

92 respectively. These frequencies are similar to common concrete nouns such as

93 "house" (rank 191), "cup" (rank 831) or "cat" (rank 1758). Children appear to

94 master the meanings of spatial prepositions, however, relatively late (Durkin, 1981),

95 especially if contextual cues are removed. In many situations, the meaning of a

96 spatial preposition can be disambiguated by context: for instance, we can put a key

97 in a cup, but we cannot put a cup in a key, and even young children will do well

98 when asked to act out an instruction such as "put the key in the cup" (Wilcox and

99 Palermo, 1975). When such cues to meaning are eliminated, however,

100 understanding of spatial prepositions is much harder. For instance, the Test for

101 Reception of Grammar -2 (Bishop, 2003) includes four multiple choice items, each 
102 of which requires a sentence such as "the flower is above the cup" to be matched to

103 the correct picture from an array. The array includes three foils depicting different

104 spatial arrangements, including one corresponding to the reversed sentence. Not

105 until nine years of age do $90 \%$ of typical children show reliable mastery of this

106 construction.

107 Bishop et al. (2006) conducted a training study that confirmed the difficulty that 108 many language-impaired children had with simple reversible sentences, even when

109 perceptual problems were unlikely to play a part because all the items were

110 acoustically distinct, familiar and shown pictorially. As with the earlier study with

111 active and passive sentences (Bishop, 1982), poor performance did not indicate a

112 total failure to understand the sentences; scores were well above the level expected

113 if the children had just been guessing. The problem, rather, was a lack of

114 automaticity in comprehending these sentences, with performance being slow,

115 effortful and error-prone.

116 This pattern of performance suggested two alternative explanations for children's

117 comprehension difficulties. One possibility is that the errors arise because of

118 problems maintaining a sentence in short-term memory while computing its

119 meaning. Verbal short-term memory is usually impaired in SLI, and it has been

120 shown to play a role in comprehension problems (Montgomery, 1995; Montgomery,

121 2000; Montgomery et al., 2010). However, the literature on this topic has focused

122 mainly on syntactically complex sentences; the question is whether poor memory

123 could limit comprehension for simple prepositional sentences comprising only three

124 key elements (e.g., $\mathrm{X}$ is below $\mathrm{Y}$ ), presented with pictorial support.

125 Another possibility is that there is difficulty learning concepts that express

126 relationship between other items. For instance, the prepositions "above" and 
127 "below" express a spatial relationship between two arguments, $\mathrm{X}$ and $\mathrm{Y}$ (e.g., $X$ is

128 above $Y ; X$ is below $Y$ ). To learn the meaning of the "_ is above =_ and "_ is below _"

129 constructions, the child must perceive the common spatial relationship that is

130 present when they are used and attach meaning to the invariant part (e.g., "is

131 above" or "is below"), so that a general, abstract meaning is understood, regardless

132 of the identity of $X$ and $Y$. Previous studies with typically-developing individuals have

133 shown that high variability facilitates detection of invariant parts of sentences

134 (Gómez, 2002). Similar results were found with typically-developing children in an

135 artificial-grammar learning study, where syntactic constructions were learned better

136 in a high variability condition than in a low variability condition, (Hsu et al., 2014).

137 However, the opposite pattern was found for age-matched children with SLI, who did

138 better in the low variability condition. This result fits with a suggestion that children

139 with SLI may have difficulty learning abstract meanings in syntactic patterns, and

140 might rely instead on rote learning of whole sentences ( $\mathrm{Hsu}$ and Bishop, 2010). Thus

141 they might learn the specific meaning of a phrase containing a preposition as a

142 whole entity (e.g., "the room above the stairs") without generalising the meaning of

143 the preposition.

144 The current study was designed to explore problems that children with SLI have in

145 understanding reversible sentences. It used a training task modelled on that used by

146 Bishop et al. (2006), but restricted to simple reversible sentences containing spatial

147 prepositions: either above/below or before/after (with a spatial interpretation). These

148 constructions were selected to correspond to the simplest type of sentence where

149 word order can disambiguate meaning. Children were trained to respond to such

150 sentences in a game-like task using an errorless learning format. Three key

151 questions were addressed in this study: 
152

153

154

155

156

157

158

159

160

161

162

163

164

165

166

167

168

169

170

\section{Participants}

172 A total of 96 children took part in the study, subdivided into four groups: a) 6 to 11

173 year-old children with SLI who received language training ( $S L I-T, N=28$ ); (b)

174 typically-developing children aged from 4 to 7 years, who were matched for raw

175 scores on a test of receptive grammar (grammar-matched controls, $\mathrm{N}=28$ ); (c)

176 typically-developing children matched for chronological age (age-matched controls,

$177 \mathrm{~N}=20$ ); and (d) 7 to 11 year-old children with SLI who did not receive language 
178 training ( $\mathrm{SLI}-\mathrm{U}, \mathrm{N}=20$ ). This is the same sample whose procedural learning skills

179 were documented by Hsu and Bishop (2014). This report focuses on groups (a) and

180 (b), i.e., the SLI and grammar-matched groups who underwent training. Data from

181 the untrained children with SLI (d) are of interest solely for identifying whether there

182 are beneficial effects of training that transfer to other tasks, in which case the

183 trained SLI group should outperform the untrained SLI group on a post-test

184 administered after training. We anticipated that the age-matched control group (c)

185 would find the reversible sentences comprehension task very easy, but they were

186 included to test this assumption.

187 The children with SLI were recruited from special schools for children with language

188 impairment or support units in mainstream schools. Children were included if they

189 met all of the following criteria:

190 (1) Performed at least 1 SD below the normative mean on at least two out of the

191 following six standardized tests: the British Picture Vocabulary Scales II (BPVS II)

192 (Dunn et al., 1997), Test for Reception of Grammar-Electronic (TROG-E) (Bishop,

193 2005), the comprehension subtest of the Expression, Reception and Recall of

194 Narrative Instrument (ERRNI), (Bishop, 2004), repetition of nonsense words from the

195 Developmental Neuropsychological Assessment (NEPSY) (Korkman et al., 1998), and

196 syntactic formulation and naming subtests of the Assessment of Comprehension and

197 Expression 6-11 (ACE 6-11), (Adams et al., 2001)

198 (2) Had nonverbal ability within the normal range (no more than 1 SD below

199 average), as measured with Raven's Coloured Progressive Matrices (Raven et al.,

200 1986)

201 (3) Were able to hear a pure tone of $20 \mathrm{~dB}$ or less in the better ear, at 500, 1000,

2022000 and $4000 \mathrm{~Hz}$ 
203 (4) Had English as their native language

204 (5) Did not have a diagnosis of other neurodevelopmental disorders such as autism 205 or Down Syndrome.

206 Children meeting the inclusion criteria for SLI were randomly assigned to either SLI-T 207 (i.e., trained group) or SLI-U (i.e., untrained group). These two SLI groups did not 208 differ in age, nonverbal IQ, or any of the standardized language tests.

209 The same test battery was used to confirm language status for children in the two 210 control groups. Both these groups met the same criteria for nonverbal IQ, hearing 211 and native language, and did not have a history of speech, language, social or 212 psychological impairments. At least five of six standardized language test scores 213 were within normal limits (no more than 1 SD below average). Descriptive 214 information on the participants is given in Table 1.

216 The children in the grammar-matched group were aged between 4 and 7 years and

217 were matched as closely as possible with the children in the SLI-T group on receptive 218 grammar using TROG-E, a standardized test that contains four four-choice test

219 items for each of twenty different syntactic contrasts (e.g., negation, subject relative 220 clause, post-modified subject, etc.), including one block that tests comprehension of 221 reversible above/below sentences. A block is scored as passed if all four items in 222 that block are correct. Each child in the grammar-matched group had a TROG-E raw 223 score within 3 blocks of one of the children in the SLI-T group.

\section{Sentence comprehension training}

225 The computerized training program was based on that used by Bishop et al. (2006).

226 Children received 4 training sessions, with one session per day over a period of 4-6 


\section{PeerJ Reviewing Manuscript}

227 days. They spent around 5-7 minutes per day on the sentence comprehension

228 program.

229 In each session, children were presented with 24 sentences containing either

230 before/after or above/below. Among the 24 sentences, there were 12 sentences that

231 occurred only once (unique items) and four sentences that appeared three times

232 across a training session (repeated items). The same repeated items were used in

233 each session (see Supplemental material). Thus, in total, children heard 48 unique

234 sentences and four sentences that were repeated 12 times across the four training

235 sessions. This manipulation allowed us to consider how sentence variability affected

236 learning in children with SLI.

237 Children were randomly assigned to be trained with reversible sentences containing

238 either before/after or above/below. Those assigned to the above/below condition

239 listened to 12 sentences containing the preposition "above" and 12 sentences

240 containing the preposition "below" in each training session. For each sentence, they

241 selected two target pictures from an array of four pictures and moved each picture

242 to an upper or a lower chamber of a space shuttle, to match the meaning of the

243 sentence (Figure 1). Children assigned to the before/after condition followed the

244 same test procedure as in the above/below condition, but were asked to move

245 pictures to the front and a back carriages of a train to indicate the spatial

246 relationship of the two target pictures.

247 A game-like format using an errorless learning procedure was adopted. If the child

248 made a correct response, there was a visible reward, with a cartoon character

249 heading a football over a bar, to add to the child's collection. If a wrong response

250 was made, the items returned to their original positions, and the child had an

251 opportunity to try again. The tester would say "Do you want to try again? Or you can 


\section{PeerJ Reviewing Manuscript}

252 click on the Help button here". The Help button provided a visual cue to indicate

253 which items needed to be selected. To minimize errors due to misperception or

254 forgetting, a Talk button was included: the tester explained to the child that when

255 this button was pressed, the test sentence would be spoken again.

256 One point was given for each trial when a correct answer was provided on the first

257 attempt by the child, even if the child had to click on the Talk button to listen to the

258 target sentence again. No points were given if the target picture was selected after

259 more than one attempt by the child or if the Help button was used. The program

260 automatically recorded timing of responses in milliseconds. Although times recorded

261 on a laptop computer are not very accurate, and likely to vary from one machine to

262 another (Plant and Quinlan, 2013), we previously found that this measure was

263 sensitive to the large within-subject changes in speed associated with training

264 (Bishop et al., 2006). For each session, the child's median response time for correct

265 responses only was taken separately for the repeated and unique item sets.

266 One to three days after training session 4, children were seen for another session

267 (session 5) in which the same computerized sentence comprehension task was

268 conducted, but using the set of prepositions (i.e., above/below or before/after) on

269 which children had not been trained. This made it possible to check whether any

270 improvement was specific to the trained preposition, or whether it generalized to a

271 different pair of prepositions.

\section{Memory measures}

273 Nonword repetition. Raw score on the NEPSY repetition of nonsense words (Korkman

274 et al., 1998) was used as a measure of phonological short-term memory. In this test,

275 children listen to 13 recorded spoken nonwords through headphones and must

276 repeat what they hear. The nonwords range in length from 2 to 5 syllables, and one 
277 point is awarded for each syllable correctly spoken. N.B. This test was also used as

278 one of the six language measures that could contribute to identification of SLI.

279 Word span. A computerized word span task was used, in which the child's task was 280 to select pictures to be placed in a horizontal line of numbered fishing nets in the 281 correct order. Children listened to lists of familiar words and saw pictures of the 282 words appear on the computer screen immediately after the auditory presentation 283 of the words. They then clicked the pictures in the same order as they had heard the 284 corresponding words. Once the first picture was clicked, it moved automatically to 285 the first fishing net, and so on for the rest of the pictures until all the pictures were 286 clicked. Items started with a list length of three, and increased by one item each 287 time the list was recalled correctly in the right order. When an incorrect response 288 was given, a second attempt at the same list length was provided. If both trials were

289 failed at list length three, a list length of two was presented. The program stopped 290 automatically when two successive trials were failed at a given list level. The 291 dependent measure was word span, i.e., the longest list length correctly reproduced 292 at least once. The word lists were composed of monosyllabic nouns that were found 293 in the lexicon of two-year-old typically-developing children (Hamilton et al., 2000).

\section{Testing schedule}

295 All children, except those assigned to the SLI-U group, were seen for two weeks 296 during which they completed two screening sessions (assessing language, hearing, 297 nonverbal IQ), followed by four sessions of language training and a post-test session 298 (see Table 2). Children in the SLI-U group were seen only for the first two screening 299 sessions and the post-test session. On the training days children were trained on 300 three computerised tasks, including the computerized sentence comprehension 301 task. The other tasks involved training vocabulary and nonverbal paired-associate 302 learning, and will be described elsewhere. One to two days after the completion of 
303 training, a post-test session was given to all children, including the SLI-U group. In

304 the post-test receptive grammar was assessed using a different parallel form of 305 TROG-E.

\section{RESULTS}

307 It would not be possible to demonstrate improvement with training for children who 308 were highly accurate in session 1 . We therefore restricted analysis of training effects 309 to those who performed below ceiling (i.e. less than $90 \%$ correct) with reversible 310 sentences on session 1 . We had anticipated that age-matched controls would find

311 this task very easy, and this proved to be the case, with only one child scoring below 312 ceiling. Accordingly the age-matched group was excluded from further

313 consideration. Of the 28 children in the SLI group, 15 (53\%) scored below $90 \%$ in the 314 first training session, as did 16 of 28 (57\%) children in the grammar-matched control 315 group. It is also of interest to consider how many children score at chance 316 indicating no understanding of the contrast. Since virtually all errors consisted of 317 selecting the correct items in the wrong order, this can effectively be treated as a 318 two-choice task, so a score of between 8-15 out of 24 correct can be regarded as 319 chance level performance (binomial theorem, $p<.05$ ). Nine of the children in the 320 SLI group and four of those in the grammar-matched group scored at chance on

321 session 1. Six children from the SLI group and twelve from the grammar-matched 322 group scored above chance but below ceiling.

323 Analysis proceeded in four stages: first, exploratory comparisons were made 324 between the children who did and did not score close to ceiling in session 1, to 325 identify characteristics of those with adequate comprehension. Second, for those 326 who scored below ceiling, we compared rates of learning for unique and repeated 
327 items in the SLI and grammar-matched groups. Third, we examined scores on the

328 post-test to check for generalization of training effects. Finally, we conducted further

329 analyses to examine memory predictors of learning.

330 Comparison of background measures for children who performed above or

331 below ceiling in session 1

332 Table 3 shows the mean age and test scores for the SLI and grammar-matched

333 groups subdivided into those who did and did not score at ceiling on training session

334 1. A two-way MANOVA was conducted on raw language scores with comprehension

335 status (above-ceiling versus below-ceiling) as one factor, and group (SLI-T versus

336 grammar-matched control) as the other. Those who scored below ceiling tended to

337 be younger, $F(1,52)=4.41, p=.041$. There were just two language measures that

338 were significantly different for the above-ceiling and below-ceiling subgroups: NEPSY

339 repetition of nonsense words, $F(1,52)=5.14, p=.027$, and ACE Syntactic

340 Formulation, $F(1,52)=4.71, p=.034)$. These same two measures also differed

341 significantly between the SLI and grammar-matched groups, NEPSY repetition of

342 nonsense words: $F(1,52)=5.15, p=.027$; ACE Syntactic Formulation, $F(1,52)=$

$3434.30, p=.043)$. Thus, although we had attempted to match the SLI and grammar-

344 matched groups on receptive syntax, the SLI children scored more poorly on a

345 measure of phonological short-term memory and on syntactic formulation, both of

346 which were measures associated with poor performance on the comprehension

347 training task. There were no significant interactions between group and ceiling

348 status: i.e., the pattern of differences for those above and below ceiling was similar

349 in the SLI and grammar-matched groups. 
350 Performance on unique and repeated sentences for children not at ceiling

351 The top panels of Figure 2 show the mean accuracy across the four training days for

352 the SLI-T and grammar-matched children who scored below ceiling ${ }^{1}$. (Data from the

353 post-test, shown as session 5, will be discussed later).

355 Data were analysed using a mixed-design ANOVA, with session ( 1 to 4 ) and item 356 type (unique vs repeated) as repeated measures, and group as between-subjects 357 factor. One potential problem with multiway analysis of variance is that the 358 probability of a Type 1 error is increased because separate null hypotheses are 359 tested (e.g., two main effects and one interaction in a 2-way design). (Cramer et al., 360 under review). To counteract this, a correction for the alpha level based on the 361 number of null hypotheses tested should be implemented. Accordingly, to correct for 362 experiment-wise error rate, we adopted a significance level of $p=.05 / 7=.007$, 363 adjusting for the three main effects and four interactions. Effects that have 364 associated $p<.05$ but $>.007$ are described as marginal.

365 Looking at main effects first, the overall effect of group was not significant: $F(1,29)$ $366=0.97, p=.332$. The effect of item type (unique vs. repeated) was not significant, $F$ $367(1,29)=3.20, p=.084$. The effect of session was significant, $F(3,87)=10.96, p$ $368<.001$, partial $\eta^{2}=.274$. Planned contrasts showed a linear effect of session 369 accounted for a high proportion of variance, indicating learning: $F(1,29)=23.6, p$ $370<.001$, partial $\eta^{2}=.449$.

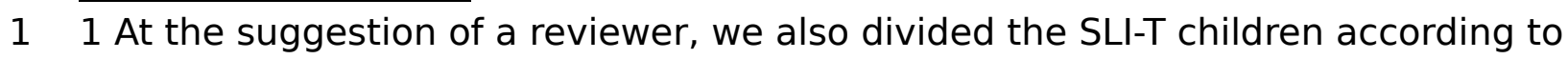

2 whether or not they scored at chance on session 1 . We found that the learning 3 profiles of these two subgroups are very similar to that based on whole group data. 
371 We next considered interactions of group with the within-subjects factors. We were

372 specifically interested in the interaction between item type and group, which was

373 non-significant, $F(1,29)=1.49, p=.231$. The interaction between session and

374 group was marginal, $F(3,87)=2.83, p=.043$. However, the three way interaction

375 between group, item type and session was significant, $F(3,87)=5.44, p=.002$,

376 partial $\eta^{2}=.158$. To explore this further, a two-way ANOVA between item type and

377 session was performed separately for each group. For the grammar-matched

378 controls, neither main effect or interaction reached significance, though there was a

379 trend for an effect of session: $F(3,45)=3.85, p=.016$. For the SLI-T group, the

380 main effect of item type was non-significant, but there was a significant effect of

381 session: $F(3,42)=9.19, p<.001$, and a significant interaction between session

382 and item type: $F(3,42)=6.38, p=.001$.

383 Finally, the difference between unique and repeated items was compared for each

384 group at each session using a matched pairs t-test with $p$ set to .05. For the SLI-T

385 group, the superiority of repeated over unique items was significant for session $2, t$

$386(14)=3.29, p=.005$, and session $3, t(14)=2.56, p=.023$, but not for the other

387 sessions. For the grammar-matched group, the difference between item types was

388 significant only for session $4, t(15)=2.46, p=.027$, but as can be seen from Figure

3892 , this reflected deterioration in performance on unique items relative to session 3 ,

390 rather than superior learning of repeated items.

391 Data on response times are shown in the lower panels of Figure 2. A test of

392 homogeneity of variances indicated significant differences in covariance matrices

393 between groups $(p=.046)$, so data were log-transformed. This led to a non-

394 significant test for homogeneity $(p=.621)$, but the session factor was significant on

395 Mauchly's test of sphericity (Mauchly's $w=.452$, d.f. $=5, p=.001$ ), so Greenhouse-

396 Geisser correction was applied. 
397 The overall effect of group was marginal, reflecting a trend for faster responses by

398 the SLI group compared to grammar-matched controls, $F(1,29)=4.46, p=.043$,

399 partial $\eta^{2}=.133$. Item type exerted a substantial effect on response times, with

400 faster responses to repeated items, $F(1,29)=75.4, p<.001$, partial $\eta^{2}=.722$, and

401 there was also a significant interaction between item type and session, $F(3,87)=$

$40210.8, p<.001$, partial $\eta^{2}=.271$. However, there was no interaction between group

403 and session or item type. Correct responses to repeated items became increasingly

404 rapid as children became more familiar with them, but this effect was equivalent in

405 children with SLI and their grammar-matched controls.

406 Post-test measures of generalization

407 Performance on session 5. Data gathered after the training allowed us to see

408 whether there had been any generalization from the training. The first source of

409 data was from session 5, in which children were given the same training game, but

410 with the preposition pair they had not been trained on (above-below or before-after).

411 Although the prepositions were new, half the items contained the noun sequences

412 that had previously been used in repeated items. Data were missing for this post-

413 test for one child in the SLI-T group. Means and standard errors for accuracy and

414 response times are shown in Figure 2 (session 5).

415 The expectation is that performance on a new preposition pair should be no better

416 than was seen in session 1, unless the child had learned some general strategy for

417 performing this kind of comprehension task. The mean scores for session 5 were

418 higher than that of session 1 for both groups, the mean (both item types combined)

419 increasing from $17.25(\mathrm{SD}=3.49)$ to $19.13(\mathrm{SD}=4.35)$ in the grammar-matched

420 group and from $14.71(S D=3.67)$ to $18.50(S D=4.29)$ in the SLI-T group. This

421 effect was examined using a mixed-design ANOVA comparing session 1 and session

4225 scores for Unique and Repeated items in SLI and grammar-matched groups. The 
423 main effect of session was significant, $F(1,28)=15.43, p=.001$, partial $\eta^{2}=.355$,

424 though neither the main effect of group nor the group by session nor the group $x$

425 item type interaction was significant. This indicates that training led to a general

426 improvement (i.e, generalization) in preposition comprehension. There was a

427 marginal interaction of session and item type, $F(1,28)=6.46, p=.017$, partial $\eta^{2}=$

428.188 . The three-way interaction of group $\mathrm{x}$ session $\mathrm{x}$ item type was not significant.

429 The marginal interaction between session and item type was unexpected, because

430 all sentences were novel in session 5 (i.e., they used a different preposition).

431 Because of its potential clinical significance, we explored this effect further, using

432 single-sample t-tests to compare gain in score with zero. The mean gain for Unique

433 items was $0.70 \pm .491$, which did not differ significantly from zero, $t(29)=1.42, p=$

434.165 . The mean gain for Repeated items was $2.07 \pm .401, \mathrm{t}(29)=5.15, \mathrm{p}<.001$.

435 The pattern of results indicated that learning of a new preposition might be

436 facilitated for all children by use of nouns they had recently been trained with.

437 A parallel analysis was conducted on log response times, comparing session 1 and 438 session 5. There was a marginal overall effect of group, reflecting faster response 439 times by the SLI group, $F(1,28)=6.13, p=.020$, partial $\eta^{2}=.180$. There was also 440 a significant 3-way interaction between group $x$ session $x$ item type, $F(1,28)=$ $4419.19, p=.005$, partial $\eta^{2}=.247$. This reflected the fact that Unique and Repeated 442 RTs did not differ significantly except for the SLI group in Session 5, whose RT was 443 faster to the Repeated items, which used the same nouns as before, but with a 444 different preposition.

445 Pre-test vs. post-test performance on TROG-E. Another way of assessing the impact 446 of training is to consider changes in overall performance on TROG-E, where different 447 parallel forms had been administered before and after the training. Table 4 shows 
448 the mean TROG-E raw scores of the age-matched controls, grammar-matched

449 controls, and the two SLI groups from the initial screening and final post-test

450 session. Children were subdivided according to whether or not they were at ceiling

451 on session 1 of the training. For the untrained SLI group we did not have the

452 information to make this distinction, so children were subdivided instead according

453 to initial TROG-E blocks passed (below 10 vs 10 or more) in order to create

454 comparable subgroups of different levels of comprehension ability. Paired t-tests

455 were conducted to determine the difference in mean scores. None of these groups

456 showed a significantly different performance in the post-test in comparison to the

457 initial test, with the SLI-T group showing a (nonsignificant) trend for worsening

458 performance. There was thus no evidence that improvement on the computerized

459 preposition training task generalized to the children's overall sentence

460 comprehension ability.

461 To further assess impact of training on TROG-E performance, for children trained on

462 the "above-below" contrast, performance on the four reversible above/below items

463 of TROG-E was compared before and after training. For the eight grammar-matched

464 children who were trained on "above" and "below", the number of correct responses

465 on TROG-E before and after training was 2.75 and 3.25 out of 4 test items, a non-

466 significant improvement $\left(t_{(7)}=-1.0, p=.35\right)$. For the eleven SLI children who were

467 trained on "above" vs "below", the performance on the four reversible above/below

468 in TROG-E was identical before and after training, with a mean of 2.27 out of 4 items

469 correct. Thus despite training with feedback on 96 sentences using this contrast, the

470 children showed no indication of having reached stable understanding of above-

471 below. 


\section{PeerJ Reviewing Manuscript}

472 Memory measures as predictors of learning on the sentence

\section{3 comprehension task}

474 Two multiple regression analyses were run using the full sample of grammar-

475 matched controls and SLI children. These examined the relationship between

476 comprehension and memory measures. First, age and raw scores on the two

477 memory measures, nonword repetition and word span, were used as predictors of

478 comprehension performance on session 1. Results are shown in Table 5. The analysis

479 was a non-hierarchical multiple regression, so the beta values indicate the extent to

480 which each variable predicts the dependent variable when all other variables have

481 been taken into account. Both of the memory measures correlated significantly with

482 day 1 comprehension to a similar extent; but nonword repetition emerged as the

483 only significant predictor in the full regression model.

484 Using the full sample has the benefit of enhancing statistical power, but the

485 disadvantage that results are somewhat skewed by inclusion of cases who scored

486 close to ceiling levels. The analysis was therefore repeated just using the 31 children

487 scoring below $90 \%$ on session 1 (lower panel of Table 5). The pattern of results was

488 similar, but correlations of memory measures with session 1 score were no longer

489 statistically significant with this smaller sample size.

490 Next, number of items correct on the last day of training (session 4) was taken as

491 the dependent measure, with number correct in session 1, age, nonword repetition

492 and word span as predictors. This analysis was run both with all 56 children

493 (including those who performed near ceiling), and with the smaller sample of 31

494 children who performed below ceiling on session 1.

495 Results for the full sample are shown in the top panel of Table 6 . The analysis 496 showed that memory span predicted amount learned (i.e., session 4 total after 
497 adjusting for session 1 total), whereas nonword repetition did not. The pattern of

498 results was the same when analysis was confined to the sample of children who

499 scored below ceiling level on session 1, although the regression coefficient for word

500 span as predictor now fell short of statistical significance.

\section{DISCUSSION}

502 Problems in comprehending short reversible sentences in children with SLI

503 Our study found that for many children with SLI, language comprehension ability

504 measured with TROG-E lags well behind their peer group. In addition, just over half

505 of these children exhibited difficulty with even short and syntactically simple

506 sentences that their age-matched peer group found extremely easy. Overall, the

507 comprehension level of children with SLI aged 8 to 9 years was comparable to

508 typically-developing children who were around three years younger.

509 Does repetition of sentences help or hinder learning of preposition

510 meanings?

511 Children with SLI who showed poor comprehension of spatial prepositions on the

512 initial training session had significantly higher scores on the repeated versus the

513 unique sentences in the second and third sessions, though they had found these

514 sentence types equally difficult in session 1 . In session 4 their performance on

515 unique items rose to be as good as for repeated items. Together, these findings

516 suggest a dynamic pattern of learning of syntactic constructions in these children

517 with SLI: they first rely on repeated items in order to gain basic understanding of

518 the meaning of specific sentence exemplars. Once they have gained some

519 understanding of the meaning of individual sentences using these prepositions, then

520 a more general meaning can be reliably extracted and generalised to new contexts.

521 In contrast, no difference between repeated and unique training sentences was seen 


\section{PeerJ Reviewing Manuscript}

522 for younger grammar-matched controls until the final training session, when,

523 unexpectedly, performance on unique items deteriorated.

524 Note that the pattern of performance that was observed in the children with SLI was

525 the opposite to what might have been predicted from artificial grammar learning

526 studies, where it has been found that variability of items facilitates learning of rule-

527 based sequences (Gómez, 2002). The SLI children, but not the grammar-matched

528 controls, were less accurate on unique than on repeated items in sessions 2 and 3.

529 This pattern is consistent with the findings of Hsu et al. (2014), who found that

530 children with SLI did better with low-variability sequences in an artificial grammar

531 learning study. $\{\mathrm{Hsu}, 2014$ \#20275\} $\{\mathrm{Hsu}, 2014 \# 20275\}$

532 In our study, however, high variability (i.e., unique items) did not benefit typically-

533 developing children either. Both groups responded faster to repeated items. To

534 explain this, we need to consider the task demands of learning an artificial grammar

535 compared with those of our training task. In a classic artificial grammar learning

536 task, all that is required is for a person to demonstrate awareness of an underlying

537 sequential structure. In our tasks, children had to assign meaning to a sequential

538 structure. For this, we suggest, repetition may facilitate performance.

539 Comprehension of a simple reversible sentence involves building a representation of

540 its syntactic and semantic structure that distinguishes between the subject of the

541 sentence and the object of the preposition, and this involves holding verbal material

542 in a memory buffer as the structural representation is generated. There are three

543 ways in which this process may be facilitated when items are repeated. First, it is

544 possible that children do not analyse the sentence structure, but simply rote learn

545 the meaning of the whole sentence: e.g., the child may learn to associate the

546 sentence: "the apple is above the horse", with a particular spatial configuration, but

547 not form an abstract representation of the meaning of "above". This explanation 
548 corresponds to the "rote learning" account of SLI proposed by Hsu and Bishop

549 (2010). A second possibility is that a string of words becomes easier to retain when

550 it is repeated (Hebbian learning), and so repetition could help counteract

551 comprehension problems due to short-term memory limitations. In another study

552 with these children, we found that Hebbian learning of noun sequences was less

553 good for those with SLI than in age-matched controls, but such learning was

554 nevertheless observed, i.e., memory was better for repeated than non-repeated

555 sequences ( $\mathrm{Hsu}$ and Bishop, 2014). A further way in which repetition may facilitate

556 performance is by priming responses to the picture-noun combinations used in the

557 task, so that the relevant pictures can be more rapidly selected. The child who hears

558 "apple" many times, will know what the picture looks like and so be able to scan for

559 and select it rapidly. This may free up cognitive capacity for computing sentence

560 meaning. This could account for the faster responses to repeated items seen in both

561 groups.

562 Prediction of comprehension from memory measures

563 Children who did poorly in comprehending short reversible sentences were similar to

564 other children in many regards but they tended to have low scores on a nonword

565 repetition test of phonological short-term memory and on a syntax formulation task.

566 Their comprehension scores at the end of training were significantly predicted by a

567 measure of memory span for words, even after taking into account their initial

568 scores in session 1 . Thus ability to remember a series of unconnected words

569 predicted how far children benefit from repeated exposure to short reversible

570 sentences containing a spatial preposition.

571 At first glance, our results may seem to contradict findings by McDonald (2008), who

572 found that word order was an aspect of grammar that was relatively impervious to

573 memory effects. However, her studies focussed on detection of grammaticality 
574 violations (such as "opens the door the man"), which pose very different demands

575 on listeners than comprehension of grammatically legal but reversible sentences.

576 Overall, our results are in line with the previous findings that poor short-term

577 memory plays a role in comprehension problems in children with SLI (Montgomery,

578 1995; Montgomery, 2000; Montgomery et al., 2010). The word span task used in the

579 current study is similar to the training task in several aspects, and this might

580 account for why only word span but not nonword repetition predicted the amount

581 learned in the training task. First, in each trial of the word span task children listened

582 to a list of familiar words (e.g., apple, star, box) instead of a single nonsense word as

583 in the nonword repetition task. Thus the word span task tested abilities more akin to

584 those involved in processing sentences composed of sequences of real words. In

585 addition, in the nonword repetition task children were required to give their

586 responses verbally, while verbal responses were not required in the word span task

587 or the training program. This difference between the two memory tasks could also

588 have contributed to the finding.

\section{Clinical implications}

590 Results from this study offer both negative and positive messages to those

591 concerned with intervention for comprehension problems. On the negative side,

592 even when training was restricted to a single pair of antonyms, performance still fell

593 below the level of age-matched controls, who made very few errors on these items.

594 Also, neither children with SLI nor their grammar-matched controls showed

595 improvement from pre- to post-test on TROG-E. A lack of transfer would be

596 consistent with the idea that children tend to learn sentence meanings by rote: such

597 knowledge would not generalize to new meanings. Nevertheless, this latter result

598 needs to be treated cautiously, given that there were only four relevant items in 
599 TROG-E; it is possible that a longer and more sensitive test of preposition

600 comprehension may have revealed some improvement. It is noted that successful

601 transfer to TROG items has been reported by Ebbels et al. (2014), who provided

602 grammatical training to a group of adolescents with receptive impairments using a

603 visual coding training strategy. The current training program differs from that used

604 by Ebbels et al. in so many different ways (e.g., including training strategies, amount

605 of training, the complexity of target structures, age of the participants, etc.) that it is

606 difficult to know which factor(s) might account for the different findings.

607 Nevertheless, it is reasonable to assume that any one of these factors could affect

608 the effectiveness of intervention in clinical settings.

609 Results from this study also offer positive messages to those concerned with

610 intervention for comprehension problems. First of all, children with SLI benefited

611 from multiple exposures to the same sentence exemplars during the initial phase of

612 intervention. This might compensate for their limitations in memory and provide the

613 children with an opportunity to build more solid representations of the first few

614 sentences they encountered before the general meaning of the related sentences

615 could be detected and learned. The ultimate goal is for children to learn the general

616 meanings of constructions such that their comprehension is not restricted to

617 sentences they have heard before; the current results suggest that when a certain

618 level of comprehension accuracy of repeated sentences is reached, different

619 sentence exemplars of the same constructions could be emphasized in order to

620 facilitate learning of general meanings. Furthermore, we found an effect of

621 generalization from the trained prepositions to a new pair of untrained prepositions,

622 and this effect was not limited to the younger grammar-matched children but was

623 also observed in the children with SLI. This finding reveals positive effects of

624 receptive grammar training that could generalize to comprehension of sentences 


\section{PeerJ Reviewing Manuscript}

625 using similar syntactic constructions. It is unclear whether or not the generalization

626 depends on a particular training format, but our results suggest that children with

627 SLI may do best if given repeated exposure to specific sentences with a given

628 sentence frame, perhaps because this facilitates rapid interpretation of the nouns in

629 the sentence, freeing up mental capacity for sentence interpretation. Accordingly,

630 generalisation to other sentences using the same syntactic frame may be more

631 effective if preceded by rote learning of specific items. In addition, when training

632 children's grammatical skills, it might be beneficial to restrict consideration to a

633 small, highly-familiar vocabulary, and not to attempt generalization to new

634 vocabulary until performance on a restricted set of items is highly reliable. It would

635 be of interest to conduct future studies examining how different presentations of

636 training stimuli affect learning of a given sentence frame and subsequent

637 generalization to a similar but different sentence type.

638 In conclusion, a high proportion of children with SLI had difficulty understanding

639 reversible sentences even when these are short and syntactically simple. It is not

640 plausible that these difficulties were due to impaired auditory perception, because

641 the words used in the sentences were simple, discriminable and illustrated with

642 pictures. Although some children performed at chance, others scored above chance,

643 indicating they had some grasp of the meanings of prepositions, but they failed to

644 perform consistently over repeated trials. The pattern of results suggested that their

645 comprehension failures may be related to weaknesses in verbal short-term memory.

646 Our study suggested that performance could be improved by computerised training

647 of sentence comprehension, incorporating rote learning of specific items in a

648 sentence frame. Nevertheless, the training regime used in this study was not

649 sufficient to bring performance up to the level of an age-matched peer group. 


\section{ACKNOWLEDGEMENTS}

651 We thank Annie Brookman, Nikki Gratton, Mervyn Hardiman, Anneka Holden,

652 Georgina Holt and Eleanor Paine and for their invaluable assistance in data

653 collection. Figure 2 was prepared by Tim Brock of datatodisplay.com. Finally, we are

654 most grateful to all the schools, families and children who participated in the study. 
656

657

658

659

660

661

662

663

664

665

666

667

668

669

670

671

672

673

674

675

676

677

678

679

680

681

682

683

684

685

686

687

688

689

690

691

692

693

694

695

696

697

698

699

700

701

702

703

ADAMS, C., COOKE, R., CRUTCHLEY, A., HESKETH, A. and REEVES, D., 2001, Assessment of Comprehension and Expression (6-11) (Windsor: NFER-Nelson).

BISHOP, D. V. M., 1979, Comprehension in developmental language disorders. Developmental Medicine and Child Neurology, 21, 225-238.

BISHOP, D. V. M., 1982, Comprehension of spoken, written and signed sentences in childhood language disorders. Journal of Child Psychology and Psychiatry, 23, 1-20.

BISHOP, D. V. M., 1997, Uncommon Understanding: Development and Disorders of Language Comprehension in Children (Hove: Psychology Press).

BISHOP, D. V. M., 2003, The Test for Reception of Grammar, version 2 (TROG-2) (London: Pearson).

BISHOP, D. V. M., 2004, Expression, Reception and Recall of Narrative Instrument (ERRNI) (London: Pearson).

BISHOP, D. V. M., 2005, The Test for Reception of Grammar, electronic version (TROG-E) (London: Pearson Assessment).

BISHOP, D. V. M., ADAMS, C. V. and ROSEN, S., 2006, Resistance of grammatical impairment to computerized comprehension training in children with specific and non-specific language impairments. International Journal of Language and Communication Disorders, 41, 19-40.

CRAMER, A. O. J., VAN RAVENZWAAIJ, D., MATZKE, D., STEINGROEVER, H., WETZELS, R., GRASMAN, R. P., WALDORP, L. J. and WAGENMAKERS, E.-J., under review, Hidden multiplicity in multiway ANOVA: Prevalence, consequences, and remedies. Downloaded from: http://www.ejwagenmakers.com/papers.html.

DUNN, L. M., DUNN, L. M., WHETTON, C. and BURLEY, J., 1997, The British Picture Vocabulary Scale, 2nd edition (BPVSII) (Windsor: NFER-Nelson).

DURKIN, K., 1981, Aspects of late language acquisition: school children's use and comprehension of prepositions. First Language, 2, 47-59.

EBBELS, S., 2007, Teaching grammar to school-aged children with specific language impairment using Shape Coding. Child Language Teaching and Therapy, 23, 67-93.

EBBELS, S. and VAN DER LELY, H., 2001, Meta-syntactic therapy using visual coding for children with severe persistent SLI. International Journal of Language and Communication Disorders, 36 Suppl, 345-350.

EBBELS, S. H., MARIC, N., MURPHY, A. and TURNER, G., 2014, Improving comprehension in adolescents with severe receptive language impairments: a randomized control trial of intervention for coordinating conjunctions. International Journal of Language and Communication Disorders, 49, 30-48.

GÓMEZ, R. L., 2002, Variability and detection of invariant structure. Psychological Science, 13, 431-436.

HAMILTON, A., PLUNKETT, K. and SCHAFER, G., 2000, Infant vocabulary development assessed with a British Communicative Development Inventory. Journal of Child Language, 27, 689-705.

HSU, H. J. and BISHOP, D. V. M., 2010, Grammatical difficulties in children with specific language impairment (SLI): is learning deficient? Human Development, 53, 264-277.

HSU, H. J. and BISHOP, D. V. M., 2014, Sequence-specific procedural learning deficits in children with specific language impairment. Developmental Science, 17, 352-365. 
704

705

706

707

708

709

710

711

712

713

714

715

716

717

718

719

720

721

722

723

724

725

726

727

728

729

730

731

732

733

734

735

736

737

738

739

740

741

742

743

HSU, H. J., TOMBLIN, J. B. and CHRISTIANSEN, M. H., 2014, Impaired statistical learning of non-adjacent dependencies in adolescents with specific language impairment. Frontiers in Psychology, 5, 1-10.

KORKMAN, M., KIRK, U. and KEMP, S. I., 1998, NEPSY: A developmental neuropsychological assessment (San Antonio: Psychological Corporation).

LEVY, $\mathrm{H}$. and FRIEDMANN, N., 2009, Treatment of syntactic movement in syntactic SLI: A case study. First Language, 29, 15-49.

MCDONALD, J., 2008, Differences in the cognitive demands of word order, plural, and subject-verb agreement constructions. Psychonomic Bulletin and Review, 15, 980-4.

MONTGOMERY, J. W., 1995, Sentence comprehension in children with specific language impairment: the role of phonological working memory. Journal of Speech and Hearing Research, 38, 189-199.

MONTGOMERY, J. W., 2000, Relation of working memory to off-line and real-time sentence processing in children with specific language impairment. Applied Psycholinguistics, 21, 117-148.

MONTGOMERY, J. W., MAGIMAIRAJ, B. M. and FINNEY, M. C., 2010, Working memory and Specific Language Impairment: An update on the relation and perspectives on assessment and treatment. American Journal of SpeechLanguage Pathology, 19, 78-94.

PLANT, R. and QUINLAN, P., 2013, Could millisecond timing errors in commonly used equipment be a cause of replication failure in some neuroscience studies? Cognitive, Affective, \& Behavioral Neuroscience, 13, 598-614.

RAVEN, J. C., COURT, J. H. and RAVEN, J., 1986, Raven's Progressive Matrices and Raven's Coloured Matrices. (London: H.K. Lewis).

RICE, M. L., WEXLER, K. and CLEAVE, P. L., 1995, Specific language impairment as a period of extended optional infinitive. Journal of Speech and Hearing Research, 38, 850-863.

RICHES, N. G., 2013, Treating the passive in children with specific language impairment: A usage-based approach. Child Language Teaching and Therapy.

VAN DER LELY, H. K. J., 1996, Specifically language impaired and normally developing children: verbal passive vs adjectival passive sentence interpretation. Lingua, 98, 243-272.

VAN DER LELY, H. K. J., 2005, Domain-specific cognitive systems: insight from Grammatical-SLI. Trends in Cognitive Sciences, 9, 53-59.

VAN DER LELY, H. K. J. and DEWART, H., 1986, Sentence comprehension strategies in specifically language impaired children. British Journal of Disorders of Communication, 21, 291-306.

WILCOX, S. and PALERMO, D. S., 1975, "In", "on" and "under" revisited. Cognition, 3, 245-254. 


\section{Table $\mathbf{1}$ (on next page)}

Mean (SD) age and test scores for four groups

Means with different superscripts differ significantly from one another on post hoc Sidak test, $p<.05$.

For Production 


\section{PeerJ Reviewing Manuscript}

\begin{tabular}{|c|c|c|c|c|}
\hline & $\begin{array}{l}\text { SLI-Trained; } \\
\mathrm{N}=28\end{array}$ & $\begin{array}{l}\text { SLI- } \\
\text { Untrained; } \\
\mathrm{N}=20\end{array}$ & $\begin{array}{l}\text { Grammar- } \\
\text { matched; } \\
\mathrm{N}=28\end{array}$ & $\begin{array}{l}\text { Age-matched } \\
N=20\end{array}$ \\
\hline Age $(y r)$ & $8.6(1.32)$ & $9.1(1.32)$ & $5.8(0.86)$ & $8.9(0.77)$ \\
\hline RCPM SS & $102.9(13.25)$ & $\begin{array}{l}100.6 \\
(10.38)\end{array}$ & $105.2(8.47)$ & $105.8(11.35)$ \\
\hline TROG-E raw blocks & $8.3(4.00)^{a}$ & $9.7(3.34)^{a}$ & $9.8(3.11)^{a}$ & $14.8(2.38)^{b}$ \\
\hline TROG-E SS & $73.3(14.29)^{\mathrm{a}}$ & $\begin{array}{l}75.7 \\
(10.64)^{a}\end{array}$ & $\begin{array}{l}102.3 \\
(13.96)^{\mathrm{b}}\end{array}$ & $97.8(10.31)^{\mathrm{b}}$ \\
\hline BPVSII raw & $69.5(17.77)^{\mathrm{a}}$ & $\begin{array}{l}75.4 \\
(14.68)^{a}\end{array}$ & $67.1(12.95)^{a}$ & $92.6(9.16)^{\mathrm{b}}$ \\
\hline BPVSII SS & $87.8(13.18)^{a}$ & $87.7(8.89)^{a}$ & $108.3(9.51)^{\mathrm{b}}$ & $102.6(7.58)^{\mathrm{b}}$ \\
\hline $\begin{array}{l}\text { NEPSY nonwords } \\
\text { raw }\end{array}$ & $22.3(8.90)^{a}$ & $23.9(8.39)^{a}$ & $27.0(7.60)$ & $32.2(8.48)^{b}$ \\
\hline NEPSY nonwords SS & $84.1(16.78)^{a}$ & $\begin{array}{l}85.5 \\
(14.13)^{a}\end{array}$ & $\begin{array}{l}104.3 \\
(15.01)^{\mathrm{b}}\end{array}$ & $101.8(15.75)^{\mathrm{b}}$ \\
\hline $\begin{array}{l}\text { ERRNI } \\
\text { Comprehension raw }\end{array}$ & $8.3(3.25)^{\mathrm{a}}$ & $9.7(3.96)^{a}$ & $8.4(3.12)^{a}$ & $12.9(2.56)^{\mathrm{b}}$ \\
\hline $\begin{array}{l}\text { ERRNI } \\
\text { Comprehension SS }\end{array}$ & $82.5(15.17)^{\mathrm{a}}$ & $\begin{array}{l}87.9 \\
(16.29)^{a}\end{array}$ & $103.0(14.6)^{\mathrm{b}}$ & $101.9(12.58)^{\mathrm{b}}$ \\
\hline ACE Naming raw & $10.2(4.32)^{\mathrm{a}}$ & $12.3(2.94)^{\mathrm{a}}$ & $10.0(2.84)^{a}$ & $16.3(3.01)^{b}$ \\
\hline ACE Naming SS & $81.6(13.2)^{a}$ & $83.8(9.16)^{a}$ & $101.1(7.98)^{\mathrm{b}}$ & $98.8(10.99)^{\mathrm{b}}$ \\
\hline ACE Syntax raw & $15.0(5.16)^{a}$ & $17.2(6.64)^{a}$ & $17.8(5.93)^{\mathrm{a}}$ & $24.1(5.13)^{\mathrm{b}}$ \\
\hline ACE Syntax SS & $80.7(9.2)^{a}$ & $83.3(13.7)^{\mathrm{a}}$ & $\begin{array}{l}105.5 \\
(14.16)^{\mathrm{b}}\end{array}$ & $98.5(15.05)^{\mathrm{b}}$ \\
\hline $\mathrm{N}$ impaired tests & $3.3(1.38)^{\mathrm{a}}$ & $3.2(1.15)^{\mathrm{a}}$ & $0.3(0.48)^{b}$ & $0.4(0.5)^{b}$ \\
\hline Word Span & $4.0(1.07)^{\mathrm{a}}$ & $4.1(0.91)^{\mathrm{a}}$ & $4.1(0.88)^{\mathrm{a}}$ & $4.9(0.79)^{b}$ \\
\hline
\end{tabular}


Table 2 (on next page)

Schedule of assessment and training

For Production 


\section{PeerJ Reviewing Manuscript}

\begin{tabular}{|c|c|c|}
\hline Day & Groups & Activity \\
\hline 1 & All & TROG-E, BPVS-II, Raven's Matrices, hearing \\
\hline & & screen \\
\hline 2 & All & Other language tests (see Table 1 ) \\
\hline 3 & All except SLI-U & Training session 1 \\
\hline 4 & All except SLI-U & Training session 2 \\
\hline 5 & All except SLI-U & Training session 3 \\
\hline 6 & All except SLI-U & Training session 4 \\
\hline 7 & All except SLI-U & Transfer of training, session 5 (untrained \\
\hline & & preposition) \\
\hline 7 & All & Posttest: BPVS-II and TROG-E (parallel form) \\
\hline
\end{tabular}


Table 3(on next page)

Mean (SD) age and test scores

SLI-T and grammar-matched groups subdivided according to whether above or below ceiling in Session 1. Means with different superscripts differ significantly from one another on post hoc Sidak test, $\mathrm{p}<.05$.

For Production 


\begin{tabular}{|c|c|c|c|c|}
\hline & $\begin{array}{l}\text { SLI-T, } \\
\text { below } \\
\text { ceiling, } \\
\mathrm{N}=15\end{array}$ & $\begin{array}{l}\text { SLI-T, } \\
\text { above } \\
\text { ceiling, } \\
\mathrm{N}=13\end{array}$ & $\begin{array}{l}\text { Grammar- } \\
\text { matched, below } \\
\text { ceiling, } \\
\mathrm{N}=16\end{array}$ & $\begin{array}{l}\text { Grammar- } \\
\text { matched, above } \\
\text { ceiling, } \\
\mathrm{N}=12\end{array}$ \\
\hline $\begin{array}{l}\text { Age (yr) } \\
\text { RCPM SS }\end{array}$ & $\begin{array}{l}8.4(1.16) \\
100.9\end{array}$ & $\begin{array}{l}8.8(1.48) \\
105.2\end{array}$ & $5.5(0.78)$ & $6.2(0.80)$ \\
\hline & $(12.52)$ & (14.18) & $103.4(8.45)$ & $107.6(8.24)$ \\
\hline TROG-E raw blocks & $7.7(2.97)$ & $9.1(4.96)$ & $8.9(3.21)$ & $10.8(2.73)$ \\
\hline TROG-E SS & 70.7 (11.26) & $76.2(17.13)$ & $103.3(13.59)$ & $101.1(14.95)$ \\
\hline BPVSII raw & $70.4(14.31)$ & $68.5(21.66)$ & $64.1(12.59)$ & $71.1(12.85)$ \\
\hline BPVSII SS & $90.5(10.48)$ & $84.5(15.54)$ & $109.3(9.97)$ & $106.8(9.09)$ \\
\hline NEPSY nonwords raw & $19.9(7.47)$ & $25.0(9.92)$ & $25.0(8.59)$ & $29.8(5.19)$ \\
\hline $\begin{array}{l}\text { NEPSY nonwords SS } \\
\text { ERRNI Comprehension }\end{array}$ & $81.0(15.26)$ & $87.7(18.33)$ & $100.9(16.35)$ & $108.8(12.27)$ \\
\hline $\begin{array}{l}\text { raw } \\
\text { ERRNI Comprehension }\end{array}$ & $7.7(3.54)$ & $8.9(2.9)$ & $7.5(3.18)$ & $9.6(2.71)$ \\
\hline SS & $82.2(15.29)$ & $82.9(15.64)$ & $102.5(13.64)$ & $103.7(16.39)$ \\
\hline ACE Naming raw & $10.0(4.88)$ & $10.4(3.75)$ & $9.8(2.67)$ & $10.4(3.12)$ \\
\hline ACE Naming SS & $83.7(14.08)$ & $79.2(12.22)$ & $102.5(7.07)$ & $99.2(9.00)$ \\
\hline ACE Syntax raw & $14.0(5.40)$ & $16.1(4.84)$ & $15.9(6.27)$ & $20.2(4.65)$ \\
\hline ACE Syntax SS & $80.7(9.61)$ & $80.8(9.09)$ & $102.8(13.90)$ & $109.2(14.28)$ \\
\hline $\mathrm{N}$ impaired tests & $3.1(1.46)$ & $3.4(1.33)$ & $0.4(0.50)$ & $0.3(0.45)$ \\
\hline Word Span & $3.7(1.05)$ & $4.3(1.03)$ & $4.0(0.89)$ & $4.3(0.87)$ \\
\hline
\end{tabular}




\section{Table 4 (on next page)}

Pre- and post-training TROG-E blocks passed

Groups subdivided according to initial level of performance on Session 1 (Age-matched, grammar-matched and SLI-T groups) or TROG-E (SLI-U group)

For Production 
PeerJ Reviewing Manuscript

\begin{tabular}{|c|c|c|c|c|c|c|c|}
\hline Group & $\begin{array}{l}\text { Initial } \\
\text { performance } \\
\text { on training } \\
\text { game }\end{array}$ & $\begin{array}{l}\text { Trained } \\
?\end{array}$ & $\mathrm{~N}$ & $\begin{array}{l}\text { Mean (SD) } \\
\text { pre }\end{array}$ & $\begin{array}{l}\text { Mean (SD) } \\
\text { post }\end{array}$ & $\mathrm{t}$ & $P$ \\
\hline Age-matched & At ceiling & Yes & 1 & 14.79 & $15.32(2.36)$ & 0.87 & .399 \\
\hline $\begin{array}{l}\text { control } \\
\text { Grammar- }\end{array}$ & Below ceiling & Yes & $\begin{array}{l}9 \\
1\end{array}$ & $\begin{array}{l}(2.44) \\
8.94(3.21)\end{array}$ & $9.94(4.02)$ & 1.71 & .108 \\
\hline $\begin{array}{l}\text { matched control } \\
\text { Grammar- }\end{array}$ & At ceiling & Yes & $\begin{array}{l}6 \\
1\end{array}$ & 10.83 & $11.42(3.68)$ & 0.71 & .492 \\
\hline $\begin{array}{l}\text { matched control } \\
\text { SLI-T }\end{array}$ & Below ceiling & Yes & $\begin{array}{l}2 \\
1\end{array}$ & $\begin{array}{l}(2.73) \\
7.67(2.97)\end{array}$ & $7.13(4.45)$ & - & .488 \\
\hline SLI-T & At ceiling & Yes & $\begin{array}{l}5 \\
1\end{array}$ & $9.08(4.96)$ & $9.85(5.14)$ & $\begin{array}{l}0.71 \\
0.70\end{array}$ & .495 \\
\hline $\begin{array}{l}\text { SLI-U } \\
\text { SLI-U }\end{array}$ & $\begin{array}{l}\text { Low TROG-E } \\
\text { High TROG-E }\end{array}$ & $\begin{array}{l}\text { No } \\
\text { No }\end{array}$ & $\begin{array}{l}3 \\
8 \\
1\end{array}$ & $\begin{array}{l}6.54(2.77) \\
11.83\end{array}$ & $\begin{array}{l}7.25(3.62) \\
12.25(2.95)\end{array}$ & $\begin{array}{l}0.58 \\
0.57\end{array}$ & $\begin{array}{l}.576 \\
.581\end{array}$ \\
\hline & & & 2 & (1.40) & & & \\
\hline
\end{tabular}


Table 5 (on next page)

Score on training session 1 ( $\max 24)$ predicted by age and memory measures (raw scores)

A. All children from grammar-matched and SLI groups $(N=56)$ B. Children from grammarmatched and SLI groups who perform below ceiling in session $1(N=31) * p<.05$ For Production 


\section{PeerJReviewing Manuscript}

A.

\begin{tabular}{|c|c|c|c|c|c|}
\hline \multirow{3}{*}{ Variable } & \multicolumn{4}{|c|}{ Zero-order $r$} & \multirow{3}{*}{ beta } \\
\hline & Age (yr) & Nonword & Word span & Session & \\
\hline & & repetition & & 1 score & \\
\hline Age (yr) & & -.20 & .16 & .13 & 16 \\
\hline Nonword rep. & & & $.32 *$ & $.34 *$ & $.29 *$ \\
\hline Word span & & & & $.35 *$ & .23 \\
\hline Mean & 7.19 & 24.6 & 4.03 & 19.1 & \\
\hline SD & 1.78 & 8.54 & 0.97 & 4.62 & $\mathrm{R}^{2}=.20$ \\
\hline
\end{tabular}

B.

\begin{tabular}{llllll}
\hline \multirow{2}{*}{ Variable } & \multicolumn{2}{l}{ Zero-order $\mathrm{r}$} & & \\
\cline { 2 - 5 } & Age (yr) & $\begin{array}{l}\text { Nonword } \\
\text { repetition }\end{array}$ & Word span & $\begin{array}{l}\text { Session } \\
1 \text { score }\end{array}$ & beta \\
\hline Age (yr) & & -.29 & .04 & -.13 & -.11 \\
Nonword rep. & & & .27 & .27 & .15 \\
Word span & & & & .35 & .32 \\
\hline Mean & 6.88 & 22.6 & 3.83 & 15.9 & \multirow{2}{*}{$=.17$} \\
SD & 1.74 & 8.34 & 0.97 & 3.84 & $\mathrm{R}^{2}=$ \\
\hline
\end{tabular}


Table 6 (on next page)

Score on training session 4 (out of 24) predicted by age, memory measures (raw scores), and session 1 score

A. All children from grammar-matched and SLI groups $(N=56)$ B. Children from grammarmatched and SLI groups who perform below ceiling in session $1(\mathrm{~N}=31) * p<.05$; ** $p<.01$ For Production 


\section{PeerJReviewing Manuscript}

A.

\begin{tabular}{|c|c|c|c|c|c|}
\hline \multirow[b]{2}{*}{ Variable } & \multicolumn{4}{|c|}{ Zero-order $r$} & \multirow[b]{2}{*}{ beta } \\
\hline & $\begin{array}{l}\text { Nonword } \\
\text { repetition }\end{array}$ & Word span & $\begin{array}{l}\text { Session } 1 \\
\text { score }\end{array}$ & $\begin{array}{l}\text { Session } \\
4 \text { score }\end{array}$ & \\
\hline $\begin{array}{l}\text { Age (yr) } \\
\text { Nonword rep. } \\
\text { Word span } \\
\text { Score day } 1\end{array}$ & -.20 & $\begin{array}{l}.16 \\
.32 *\end{array}$ & $\begin{array}{l}.14 \\
.33^{*} \\
.35^{* *}\end{array}$ & $\begin{array}{l}.19 \\
.16 \\
.45^{* *} \\
.46^{* *}\end{array}$ & $\begin{array}{l}.08 \\
-.06 \\
.33^{*} \\
.35^{* *} \\
\mathrm{R}^{2}=.31\end{array}$ \\
\hline
\end{tabular}

B.

\begin{tabular}{|c|c|c|c|c|c|}
\hline \multirow[b]{2}{*}{ Variable } & \multicolumn{4}{|c|}{ Zero-order $r$} & \multirow[b]{2}{*}{ beta } \\
\hline & $\begin{array}{l}\text { Nonword } \\
\text { repetition }\end{array}$ & Word span & $\begin{array}{l}\text { Session } 1 \\
\text { score }\end{array}$ & $\begin{array}{l}\text { Session } \\
4 \text { score }\end{array}$ & \\
\hline $\begin{array}{l}\text { Age (yr) } \\
\text { Nonword rep. }\end{array}$ & -.29 & $\begin{array}{l}.04 \\
.27\end{array}$ & $\begin{array}{l}-.14 \\
.27\end{array}$ & $\begin{array}{l}.21 \\
0\end{array}$ & $\begin{array}{l}.24 \\
-.14\end{array}$ \\
\hline $\begin{array}{l}\text { Word span } \\
\text { Score day } 1\end{array}$ & & & .35 & $\begin{array}{l}.43^{*} \\
.42^{*}\end{array}$ & $\begin{array}{l}.34 \\
.38^{*}\end{array}$ \\
\hline & & & & & $\mathrm{R}^{2}=.34$ \\
\hline
\end{tabular}




\section{Figure 1}

Sample screenshot from comprehension training program

The child hears a sentence such as "the hedgehog is above the boot", and must click first on the hedgehog and then on the boot to move them into correct positions in the rocket. The question mark denotes the next position to be filled. The child can press "talk" to have the sentence repeated, and can press "help" to have visual cues added to denote which items must be moved. The format for the preposition pair "before/after" was identical except that a train was shown, and the task was to select items to fill trucks of the train in the correct horizontal order 

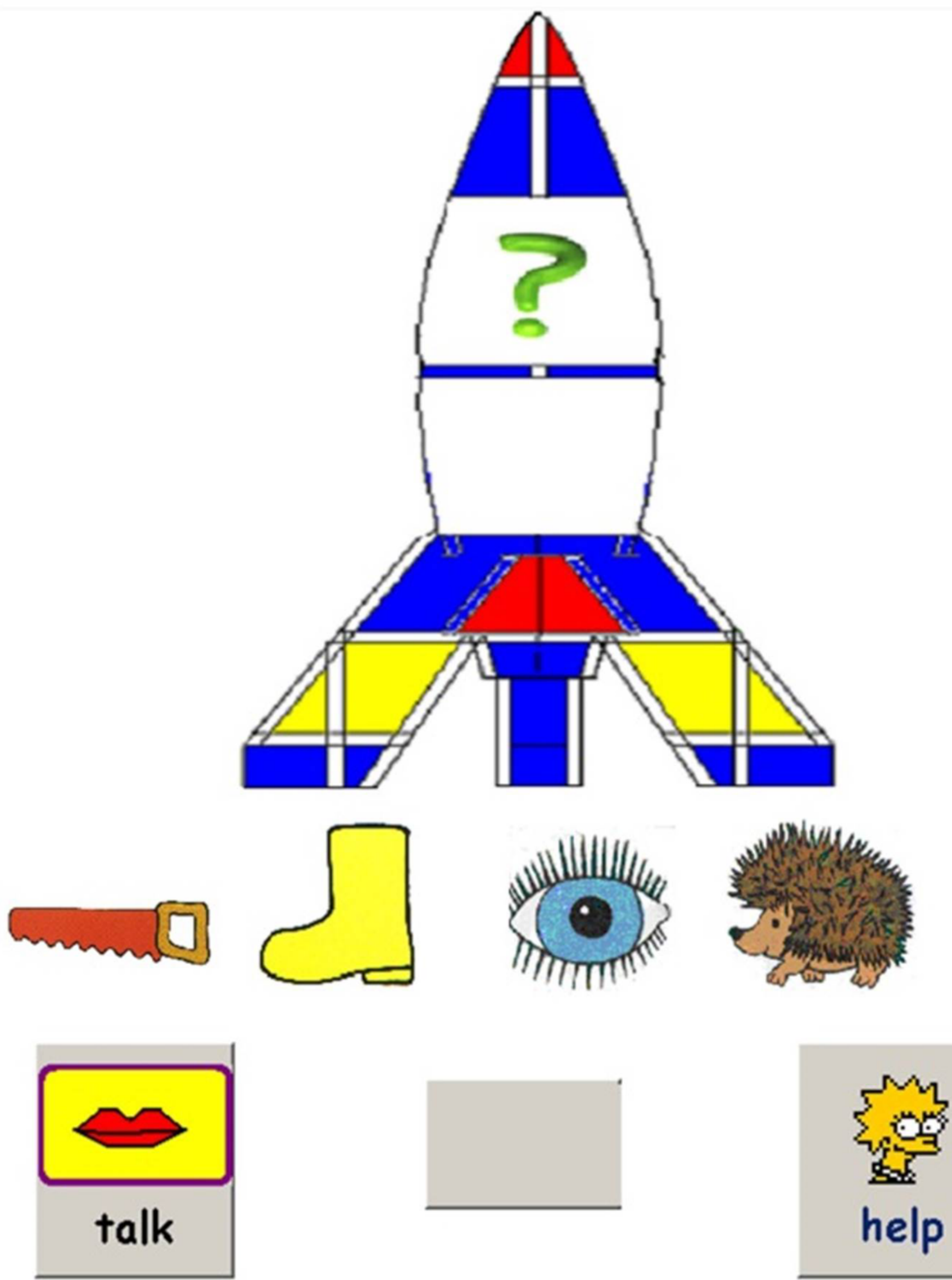


\section{Figure 2}

Mean items correct and response times across four training sessions and a post-test session (5) for children who scored below $90 \%$ correct on session 1

Panels $A$ and $B$ show mean items correct, and Panels $C$ and $D$ show response times. Grammar-matched children in panels A and C and SLI-T in panels B and D. Error bars show standard errors.

Grammar-matched

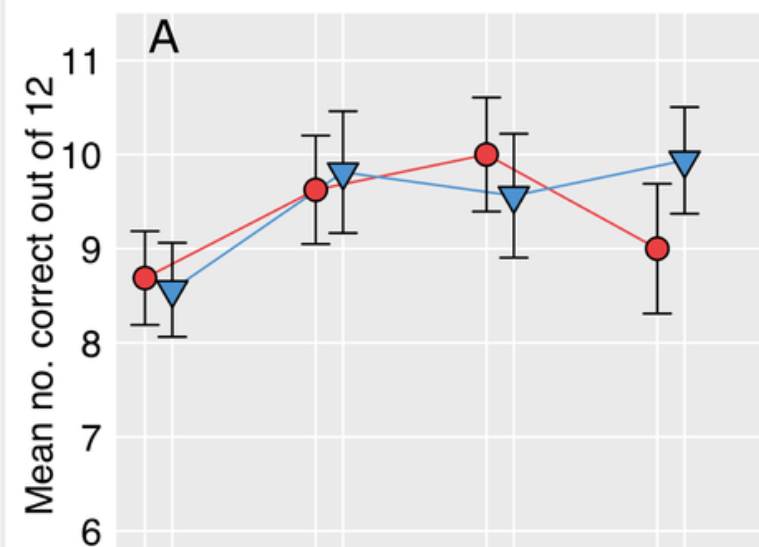

$12 \begin{array}{lll}3 & 4\end{array}$

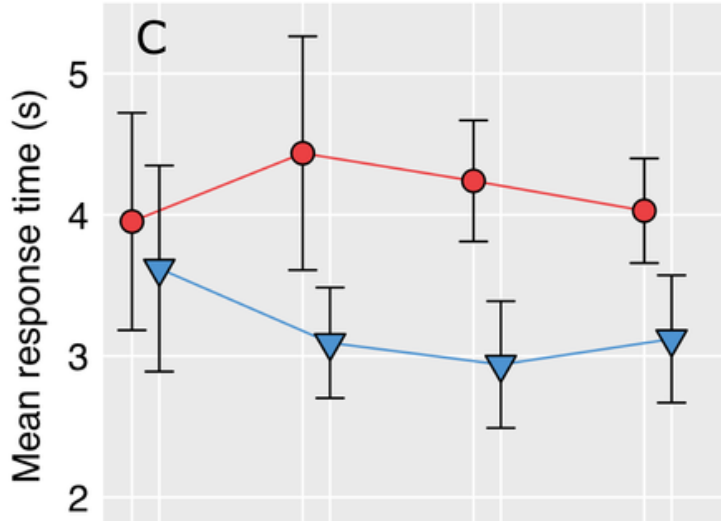

1
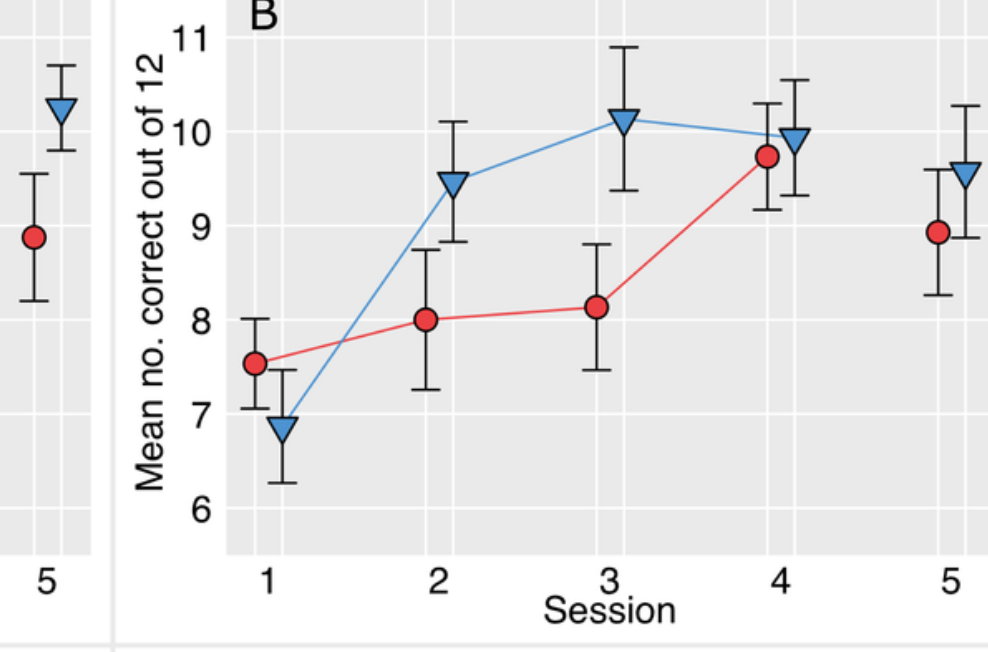

B

SLI

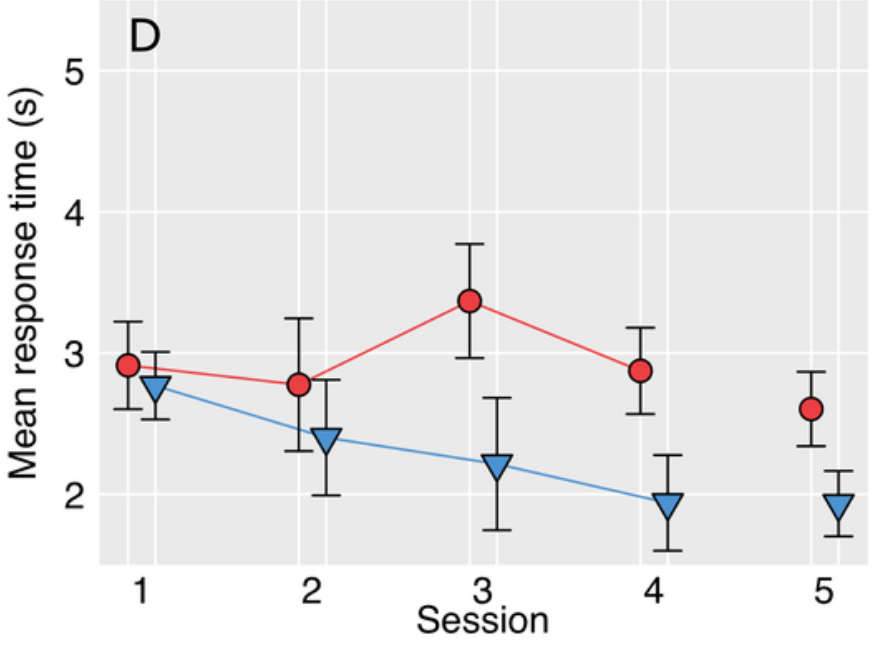

O Unique $\quad \nabla$ Repeated 